\title{
LA AGRAVANTE DE DISCRIMINACIÓN POR RAZONES DE GÉNERO FUERA DEL ÁMBITO DE LA PAREJA O EXPAREJA. COMENTARIO A LA SENTENCIA DEL TRIBUNAL SUPREMO NÚMERO 444/2020, DE 14 DE SEPTIEMBRE
}

\author{
Néstor Orejón Sánchez de las Heras \\ Universitat de València
}

Title: The aggravating circumstance of gender discrimination outside the scope of the couple or expartner. A commentary on Supreme Court Judgment 444/2020 of 14 September

Resumen: La reforma del Código Penal de 2015 introdujo en el texto punitivo las razones de género como motivo de aplicación de la agravante genérica de discriminación reconocida en el art. 22.4 ${ }^{\mathrm{a}}$. Los supuestos en los que puede concurrir, como consecuencia de su relación con los tipos género específicos regulados con ocasión de la Ley Orgánica 1/2004, no son pacíficos por lo que se ha generado debate en torno a si esta circunstancia puede ser aplicable a los supuestos en los que no existe o ha existido vínculo conyugal o relación sentimental análoga a esta, presente o pasada, entre los sujetos intervinientes. Después de varias sentencias dictadas por el Tribunal Supremo, alguna de ellas confusa e incluso contradictoria en este sentido, recientemente se ha podido pronunciar expresamente mediante STS 444/2020, de 14 de septiembre, por lo que el presente estudio pretende analizar esta resolución judicial, así como su encaje en la doctrina y la evolución jurisprudencial.

Palabras clave: discriminación por razones de género; violencia de género; derecho penal.

Abstract: The reform of the Criminal Code in 2015 introduced gender as a ground for applying the generic aggravating circumstance of discrimination recognized in art. $22.4^{a}$ article. The cases in which it may concur, as a result of its relationship with the specific gender types regulated on the Organic Law 1/2004, are not undisputed. As a consequence, a debate 
has arisen as to whether this circumstance may be applicable to cases in which there is or has been no conjugal bond nor sentimental relationship comparable to this, either present or past relationship, between the subjects concerned. The Supreme Court, after several judgments, some of them confusing and even contradictory in this respect, has recently been able to express itself through STS 444/2020 of 14 September. This contribution aims to analyze this judicial decision as well as its relevance to legal doctrine and jurisprudence.

Keywords: Discrimination Based on Gender; Gender Violence; Criminal Law.

SUMARIO: 1 . Introducción. - 2. Aproximación a la agravante genérica de discriminación por razones de género. - 3. Desarrollo jurisprudencial. - 3.1. Ámbito de aplicación. - 3.1.1 relación entre los sujetos activo y pasivo del delito. - 3.1.2. El hombre como sujeto pasivo del delito. - 3.2. Elemento subjetivo. - 4. Consideraciones finales. - Bibliografía citada. - Jurisprudencia citada.

\section{Introducción}

A diferencia de lo que ocurría en el Código Penal de 1973, en la actualidad los delitos contra la libertad sexual no establecen la necesidad de que el sujeto pasivo sea mujer. La Ley Orgánica 3/1989, de 21 de junio, de actualización del Código Penal, vino a modificar esta situación sustituyendo la rúbrica de delitos contra la honestidad por delitos contra la libertad sexual y, desde entonces, "la protección se otorga, por igual, a hombres y mujeres, sin que se requiera condición alguna para otorgar la protección ni se admita exclusión de la misma por mor de la concurrencia de circunstancias o situaciones que no deben de afectar al ejercicio de la libertad, como por ejemplo si se da la circunstancia de ejercer la prostitución o el ataque a la libertad se produce en el marco de relaciones matrimoniales o de análoga relación de afectividad" (Boix, 2003: 10).

No obstante, atendiendo a la realidad social estas infracciones penales se conforman como "delitos donde los ataques estadísticamente generan que hablemos de bienes jurídicos de eminente titularidad femenina" (Lloria García, 2020: 327). En este sentido, el Instituto de la Mujer y para la Igualdad de Oportunidades, tomando como fuente el Anuario Estadístico del Ministerio del Interior, concluye que en el año 2016, el 82,89\% de los sujetos pasivos de delitos contra la libertad sexual, fueron mujeres ${ }^{1}$ y la Macroencuesta de Violencia contra la Mujer 2019 publicada por la

1 Puede consultarse el anuario en https://www.inmujer.gob.es/MujerCifras/Violencia/ DelitosLibertadSexual.htm 
Delegación del Gobierno contra la Violencia de Género del Ministerio de Igualdad $^{2}$ indica que del total de mujeres de 16 o más años residentes en España, el 6,5\% ha sufrido violencia sexual en algún momento de su vida de alguna persona con la que no mantiene ni ha mantenido una relación de pareja y el $8,9 \%$ ha sufrido violencia sexual de alguna pareja actual o pasada en algún momento de su vida.

La alta prevalencia sobre las mujeres de este tipo de delitos ha supuesto que los delitos contra la libertad sexual hayan sido considerados por el movimiento feminista como un "síntoma de opresión [y] como un problema estructural derivado de la construcción social y de los roles asignados en función del sexo" (Valeije, 1999: 314). Esto es fruto de los roles de género establecidos en una sociedad patriarcal en la que la sexualidad de la mujer está al servicio de la satisfacción de los deseos del hombre y para la reproducción.

Aunque el legislador no contempló en la LO 1/2004, de 28 de diciembre, de Medidas de Protección Integral contra la Violencia de Género (LMPIVG), ningún tipo género específico en relación con los delitos contra la libertad sexual, lo cierto es que la Convención sobre la eliminación de todas las formas de discriminación contra la mujer de Naciones Unidas, de 11 de mayo de 2011, ratificada por España (Convenio de Estambul ${ }^{3}$ ), presta especial atención a estas infracciones penales, de modo que en su artículo $36^{4}$ prevé la necesidad de que los Estados parte adopten las medidas legislativas o de otro tipo que se estimen necesarias para luchar contra este tipo de violencia que afecta de una manera desproporcionada a las mujeres.

Así, la incorporación de la circunstancia agravante de discriminación por razones de género y su posible concurrencia en los delitos contra la libertad sexual parece dar cumplimiento a las obligaciones internacionales asumidas por España en la lucha contra la violencia sobre la mujer. No obstante, el Tribunal Supremo no había tenido ocasión de pronunciarse

2 Macroencuesta accesible en el enlace web: https://violenciagenero.igualdad.gob.es/ violenciaEnCifras/macroencuesta2015/pdf/Macroencuesta_2019_estudio_investigacion.pdf.

3 Convenio del Consejo de Europa sobre prevención y lucha contra la violencia contra las mujeres y la violencia doméstica, hecho en Estambul, el 11 de mayo de 2011, ratificado por España el 10 de abril de 2014, publicado en el BOE núm. 137, de 6 de junio de 2014, y en vigor para nuestro país desde el 1 de agosto de 2014. En adelante, "Convenio de Estambul".

4 Establece el artículo 36 del Convenio, bajo el título "Violencia sexual, incluida la violación”, que: “1. Las Partes adoptarán las medidas legislativas o de otro tipo necesarias para tipificar como delito, cuando se cometa intencionadamente: a) la penetración vaginal, anal u oral no consentida, con carácter sexual, del cuerpo de otra persona con cualquier parte del cuerpo o con un objeto; b) los demás actos de carácter sexual no consentidos sobre otra persona; c) el hecho de obligar a otra persona a prestarse a actos de carácter sexual no consentidos con un tercero. 2. El consentimiento debe prestarse voluntariamente como manifestación del libre arbitrio de la persona considerado en el contexto de las condiciones circundantes. 3. Las Partes adoptarán las medidas legislativas o de otro tipo necesarias para que las disposiciones del apartado 1 se apliquen también contra los cónyuges o parejas de hecho antiguos o actuales, de conformidad con su derecho interno”. 
respecto a la posible aplicación de esta agravante genérica en supuestos de hecho en los que no existiera entre los sujetos intervinientes una relación matrimonial o sentimental presente o pasada en el momento de los hechos objeto de calificación, habiéndose planteado dudas y posicionamientos encontrados en sus sentencias previas y en la doctrina.

La Sentencia del Tribunal Supremo número 444/2020, de 14 de septiembre, viene precisamente a confirmar la concurrencia de la circunstancia agravante de discriminación por razones de género en un supuesto de violación y establece su posicionamiento, en este sentido, sobre algunas de las cuestiones que se venían discutiendo al respecto de la misma. Especialmente se va a pronunciar en cuanto al ámbito de aplicación según los sujetos intervinientes y en relación con el elemento subjetivo de la circunstancia modificativa.

\section{Aproximación a la agravante genérica de discriminación por razones de género}

La Ley Orgánica 1/2015, de 30 de marzo, modificó el Código penal e introdujo, en la circunstancia agravante genérica de discriminación regulada en el artículo 22.4 , las razones de género como uno de los motivos contenidos en el listado numerus clausus de dicho precepto para justificar la concurrencia de esta agravación de la pena ${ }^{5}$. Reforma en materia de violencia sobre la mujer que, como en su propio preámbulo indica, tiene su origen en el Convenio de Estambul.

Este tratado internacional, que constituye el primero con carácter vinculante en materia de violencia de género en Europa (Gallego Sánchez, 2015), por un lado, en el artículo 46, titulado "Circunstancias agravantes", conmina a los Estados parte en la Convención a fin de que procedan a adoptar las medidas legislativas o de otro tipo necesarias para introducir en sus correspondientes ordenamientos jurídicos penales una serie de circunstancias que agraven la responsabilidad criminal. Al mismo tiempo que, por otro, en su artículo 3 establece una serie de definiciones sobre género ${ }^{6}$, violencia contra las mujeres ${ }^{7}$ y violencia contra las

5 Aunque esta reforma introdujo las 'razones de género' en diversos preceptos relacionados con los delitos por discriminación, el presente trabajo se limita al art. 22.4 ${ }^{\mathrm{a}}$ del Código Penal al ser el afectado por la STS 444/2020, objeto del presente comentario.

6 Art. 3.c: “por 'género' se entenderán los papeles, comportamientos, actividades y atribuciones socialmente construidos que una sociedad concreta considera propios de mujeres o de hombres".

7 Art. 3.a: "por 'violencia contra las mujeres' se deberá entender una violación de los derechos humanos y una forma de discriminación contra las mujeres, y designará todos los actos de violencia basados en el género que implican o pueden implicar para las mujeres daños o sufrimientos de naturaleza física, sexual, psicológica o económica, incluidas 
mujeres por razones de género ${ }^{8}$ que establecen un ámbito de aplicación más amplio que el reconocido, hasta ese momento, en nuestro Código penal en virtud de los tipos género específicos establecidos mediante la Ley Orgánica 1/2004, de 28 de diciembre, de Medidas de Protección Integral contra la Violencia de Género, al no circunscribirse exclusivamente a las relaciones de pareja o expareja ${ }^{9}$.

La interpretación restrictiva del concepto de violencia de género en nuestro ordenamiento jurídico penal había sido objeto de preocupación en las últimas Observaciones finales del CEDAW sobre los informes periódicos de España ${ }^{10}$, emitidas en el año 2015. En ellas, expresamente se indicaba que la "Ley Orgánica núm. 1/2004 no abarca la gama completa de la violencia de género fuera de la violencia dentro de la pareja”, motivo por el que se instaba a España a "revisar su legislación sobre la violencia contra la mujer en vigor a fin de que incluya otras formas de violencia de género, por ejemplo, la violencia ejercitada por cuidadores, la violencia policial y la violencia en espacios públicos, lugares de trabajo y escuelas".

Por todo ello, y pese a que inicialmente el proyecto de ley no contemplaba la inclusión en el Código penal del motivo discriminatorio basado en "razones de género", durante la tramitación parlamentaria, y con ocasión de una enmienda del Grupo Parlamentario Popular, la Ponencia del proyecto de ley aceptó la misma y admitió la incorporación de las razones de género en la agravante genérica de discriminación. De este modo, la Comisión de Justicia propuso con posterioridad su inclusión en la circunstancia $4^{\mathrm{a}}$ del artículo 22 del Código Penal y tal y como es propuesta será finalmente aprobada por el Congreso y por el Senado.

Así, la introducción de las razones de género como una de las clases de discriminación se justifica en el propio Preámbulo de la ley en la diferenciación entre el sexo y el género y la diferente fundamentación en uno y otro supuesto. De modo expreso, el epígrafe XXII del Preámbulo indica que "el género, entendido de conformidad con el Convenio $n^{\circ} 210$ del Consejo de Europa sobre prevención y lucha contra la violencia contra las mujeres y la violencia doméstica, aprobado en Estambul por el

\footnotetext{
las amenazas de realizar dichos actos, la coacción o la privación arbitraria de libertad, en la vida pública o privada".

8 Art. 3.d: 'por 'violencia contra las mujeres por razones de género' se entenderá toda violencia contra una mujer porque es una mujer o que afecte a las mujeres de manera desproporcionada".

$9 \mathrm{El}$ art. 1.1 de esta ley indica expresamente que la misma "tiene por objeto actuar contra la violencia que, como manifestación de la discriminación, la situación de desigualdad y las relaciones de poder de los hombres sobre las mujeres, se ejerce sobre éstas por parte de quienes sean o hayan sido sus cónyuges o de quienes estén o hayan estado ligados a ellas por relaciones similares de afectividad, aun sin convivencia".

10 Observaciones finales sobre los informes periódicos séptimo y octavo combinados de España examinados en las sesiones 1308 y 1310 del Comité aprobadas en fecha 29 de julio de 2015.
} 
Comité de Ministros del Consejo de Europa el 7 de abril de 2011, como 'los papeles, comportamientos o actividades y atribuciones socialmente construidos que una sociedad concreta considera propios de mujeres o de hombres', puede constituir un fundamento de acciones discriminatorias diferente del que abarca la referencia al sexo".

De este modo, la regulación de la violencia de género en nuestro Código penal apuesta por un modelo político criminal mixto, en el que se van a establecer, por un lado, tipos género específicos ${ }^{11}$ expresamente reconocidos en función de su frecuencia comisiva ${ }^{12}$ y delimitados por la violencia que se ejerce en el seno de la pareja o expareja, y, por otro, una circunstancia agravante genérica de discriminación por razones de género. No obstante, hay que tener en cuenta que esta última no se constituye como una nueva e independiente circunstancia, sino mediante la inclusión de esta motivación como una más de las descritas en el precepto penal, lo que supone necesariamente que hay que tener en cuenta el desarrollo jurisprudencial y doctrinal previo de la agravante.

Parece de este modo, como consecuencia de la motivación del legislador, que, al margen de los tipos penales genero específicos, los delitos cometidos por razones de género no van a limitarse a aquellos que se cometen en el seno de la pareja o expareja sino que, en los términos del Convenio de Estambul, se aplicará a aquellos supuestos en los que el autor ha actuado por motivos discriminatorios contra el sujeto pasivo por razón de los papeles, comportamientos, actividades y atribuciones socialmente construidos que una sociedad concreta considera propios de mujeres o de hombres, con independencia de las relaciones existentes entre los sujetos intervinientes. Hechos en los que no será necesario que exista o haya existido una relación de tipo conyugal o afectiva entre los sujetos activo y pasivo.

No obstante, la introducción de este motivo en la circunstancia agravante genérica de discriminación sin haber procedido a modificar la descripción sobre qué se entiende por violencia de género en el art. 1 de la LMPIVG, ha supuesto que algunos autores entiendan que hay que vincular esta definición con el nuevo concepto introducido mediante LO 1/2015, y así indican que atendiendo a "una interpretación teleológica-sistemática es obligado circunscribir el ámbito de aplicación de la circunstancia agravante de discriminación por razones de género a la violencia

11 En concreto, los delitos de lesiones (art. $148.4^{\circ} \mathrm{CP}$ en relación con el art. 147 del mismo texto legal), malos tratos (art. 153.1 CP), amenazas (art. 171.4 CP) y coacciones $(172.2 \mathrm{CP})$.

12 En este sentido, refiere Laurenzo Copello que "la selección de las conductas punibles no se hizo en función de su gravedad, sino de su frecuencia comisiva. De ahí que las agravantes de género se encuentren en delitos tales como el maltrato de obra que no produce lesiones, las lesiones leves o las amenazas y coacciones también leves y en cambio no exista un delito de feminicidio asociado a los tipos penales contra la vida” (Laurenzo Copello, 2015: 786). 
ejercida por un hombre sobre su pareja o expareja mujer, tal y como dispone el art. 1 de la Ley Orgánica 1/2004" (Rueda Martín, 2019: 23).

Hasta la Sentencia número 444/2020, de 14 de septiembre, el Tribunal Supremo se había pronunciado al respecto de la aplicación de esta agravante genérica únicamente en supuestos en los que entre el sujeto activo y el sujeto pasivo existía o había existido una relación conyugal o análoga a esta, siendo que en alguna ocasión había hecho referencia a otro tipo de supuestos. No obstante, lo había hecho de manera contradictoria, como se tendrá ocasión de exponer infra.

Por otro lado, la circunstancia genérica de discriminación requiere acreditar, a través de su conducta o manifestación externa, la determinante motivación discriminatoria del sujeto activo (Ganzenmüller Roig, Escudero Moratalla y Frigola Vallina, 2000: 232). El propio Tribunal Supremo ya tenía establecido que "lo que caracteriza la circunstancia es que el racismo, el antisemitismo o cualquier sentimiento discriminatorio, sea el motivo de cometer el delito" ${ }^{13}$. Pese a ello, en las resoluciones judiciales dictadas por este tribunal con carácter previo a la sentencia objeto de estudio, ya se había reinterpretado este extremo para la concreta circunstancia agravante de discriminación por razones de género en el ámbito de la pareja o expareja teniendo la oportunidad en esta ocasión de pronunciarse sobre el elemento subjetivo cuando el motivo de discriminación corresponde a razones de género pero entre los sujetos intervinientes no concurre esa relación personal presente o pasada.

La circunstancia agravante objeto de estudio plantea otro tipo de conflictos dogmáticos, como es la compatibilidad con la circunstancia mixta de parentesco. Sobre este extremo, algunos autores entendían que la introducción del género en el artículo $22.4^{\mathrm{a}} \mathrm{CP}$ supondría un desplazamiento de la circunstancia mixta (Díaz López, 2015), de modo que habría que concluir que "a partir de la entrada en vigor de la reforma, los hechos punibles perpetrados por el hombre frente a su pareja o expareja, haya sido legal o de hecho, se agravarán conforme al art. 22.4 ${ }^{\mathrm{a}}$ y no por el 23, que debiera haber sido reformado para evitar la duplicidad de regulaciones" (Borja Jiménez, 2015: 122). No obstante, lo cierto es que "la jurisprudencia de manera unánime entiende que, dado que la fundamentación de las circunstancias contenidas en los artículos 23 y 22.4 es diferente, no hay ningún obstáculo en declarar su compatibilidad, por lo que es posible su concurrencia en el caso de que el hecho no contemple en el diseño de su injusto la relación especial en los sujetos -pues obviamente en otro caso se produciría la vulneración del principio ne bis in idem-, si a la situación de discriminación se suma la relación de pareja” (Lloria García, 2019: 12).

13 STS núm. 1145/2006, de 23 de noviembre. 
No obstante, dado que el presente trabajo versa sobre la Sentencia del Tribunal Supremo número 444/2020, de 14 de septiembre, se limitará a su ámbito de aplicación por los sujetos intervinientes y al elemento subjetivo de necesaria concurrencia.

\section{Desarrollo jurisprudencial}

Hasta la fecha, el Tribunal Supremo ha tenido ocasión de pronunciarse en relación con la circunstancia agravante de discriminación por razones de género en dieciséis ocasiones ${ }^{14}$, si bien solo en la última de ellas lo ha hecho en un supuesto en el que entre el sujeto activo y el sujeto pasivo no concurría una relación conyugal o análoga a esta, pasada o presente, sino que los hechos se producen en un contexto de relaciones sexuales a cambio de precio.

En esta última sentencia, de 14 de septiembre de 2020, y después de los pronunciamientos precedentes del tribunal en los que ya había hecho alguna referencia a un ámbito relacional ajeno a la pareja o expareja, se razona tanto si es posible aplicar la circunstancia genérica en estos supuestos como si debe concurrir un elemento subjetivo específico entendido como la expresa voluntad del sujeto activo de someter a subordiscriminación ${ }^{15}$ al sujeto pasivo.

\section{1. Ámbito de aplicación}

El primero de los conflictos que resuelve la sentencia objeto del presente artículo, en cuanto a la circunstancia agravatoria, es el ámbito de aplicación en cuanto a los sujetos intervinientes en la acción típica.

Por un lado, esta última sentencia del Tribunal Supremo viene a considerar que puede concurrir la circunstancia agravante genérica de discriminación por razones de género en supuestos en los que no hay relación de afectividad presente o pasada entre los sujetos activo y pasivo. Pero, por otro, sigue pendiente el posicionamiento del tribunal sobre si es necesario que el sujeto pasivo sea mujer. Extremo este último sobre el que se pronuncia la Sentencia número 12/2020, de 23 de enero.

14 No obstante, hay que indicar que la primera de ellas, esto es, la STS 79/2016, de 10 de febrero, hace referencia a unos hechos anteriores a la entrada en vigor de la circunstancia agravante genérica de discriminación por razones de género. Así, aunque llega a hacer referencia a ella y a valorar algunos extremos de la misma, en su FJ undécimo indica que no "resulta aplicable la nueva agravante de 'razones de género', que aún no se encontraba en vigor cuando ocurrió el hecho".

15 Sobre el concepto de subordiscriminación, resulta de interés De Lucas Martín (2020: 69). 


\subsubsection{Relación entre los sujetos activo y pasivo del delito}

El supuesto de hecho parte de una relación ajena a la sentimental entre el sujeto activo (hombre) y el sujeto pasivo (mujer), en concreto en un contexto de relaciones sexuales a cambio de precio. Así, el condenado establece un contacto inicial solicitando servicios sexuales a la mujer $\mathrm{y}$, posteriormente, aprovecha esta situación para acometer a la misma llevando a cabo un ataque contra su libertad sexual que es calificado como delito de agresión sexual con la concurrencia de la circunstancia agravante de género (además de un delito de lesiones y un delito de robo con violencia e intimidación a los que no se les aplica esta agravante).

El Tribunal Supremo había tenido ocasión de pronunciarse al respecto en sentencias precedentes que, aun no haciendo referencia a supuestos de hecho ajenos a la relación sentimental requerida por el art. 1 de la LO $1 / 2004$, se pronunciaban en sentidos divergentes incluso en resoluciones muy cercanas cronológicamente, manteniendo así la discrepancia existente igualmente en la doctrina.

De este modo, la Sentencia 420/2018, de 25 de septiembre, parece establecer que para que pueda ser aplicable la agravación de la pena introducida mediante LO 1/2015, debe concurrir la relación sentimental, presente o pasada, entre los sujetos. Así, indica expresamente en su fundamento jurídico primero, epígrafe segundo, que la agravante genérica resulta de aplicación en todos aquellos casos en los que "la discriminación por esas razones, basadas en la intención de dominación del hombre sobre la mujer, que dentro de las relaciones de pareja es considerada por el autor como un ser inferior, vulnerando, por lo tanto, su derecho a la igualdad, aparezcan como motivos o móviles de la conducta". Posicionamiento que reitera en su Sentencia 584/2018, de 23 de noviembre (fundamento jurídico sexto). En este sentido se pronuncia Marín de Espinosa cuando refiere que la agravante genérica por razones de género exige dos elementos, siendo uno de ellos "que el hecho sea cometido en el ámbito de las relaciones de matrimonio o análogas de afectividad, ya sean presentes o pasadas" (Marín de Espinosa Ceballos, 2018: 18).

Por el contrario, entre otras, en la Sentencia número 565/2018, de 19 de noviembre, deja abierta la aplicación de la circunstancia a situaciones ajenas a una relación conyugal o análoga a esta, presente o pasada, cuando en el fundamento jurídico séptimo indica expresamente que "se lleva a cabo una situación de subyugación del sujeto activo sobre el pasivo, pero sin concretarse de forma exclusiva el ámbito de aplicación de la agravante sólo a las relaciones de pareja o ex pareja, sino en cualquier ataque a la mujer con efectos de dominación, por el hecho de ser mujer. Esta es la verdadera significación de la agravante de género".

En este mismo sentido resulta contundente la Sentencia número 99/2019, de 26 de febrero, cuando justifica en su fundamento jurídico 
tercero la inexigibilidad de concurrencia de una relación previa entre los sujetos cuando determina que "nada obliga a limitar la agravante a los casos de esa relación de pareja. La Ley Orgánica 1/2004 de protección integral, pese a que la intervención penal que introduce la circunscribe a ese concreto ámbito, define en el primero de los párrafos de su exposición de motivos la violencia ‘de género' diciendo que: 'Se trata de una violencia que se dirige sobre las mujeres por el hecho mismo de serlo, por ser consideradas, por sus agresores, carentes de derechos mínimos de libertad, respeto y capacidad de decisión’. La Ley Orgánica 1/2015 si bien determinados tipos penales los acota a supuestos en que la mujervíctima mantiene con, o ha mantenido con el agresor una relación de pareja, cuando describe la agravante que aquí nos ocupa, no efectúa esa restringida delimitación. Por ello su ámbito de aplicación extravasa dicha relación de pareja”.

Este último posicionamiento jurisprudencial es el que asume la Sentencia número 444/2020, de 14 de septiembre, en la que confirma que "el ámbito de aplicación de la agravante de discriminación por razones de género extravasa las relaciones conyugales o de pareja”. Conclusión a la que llega partiendo de que la introducción de este concreto motivo discriminatorio en la circunstancia agravante mediante LO 1/2015 trae causa de la ratificación por España del Convenio de Estambul en cuyo art. $2^{\circ}$ se remite a todas las formas de violencia contra las mujeres, incluida la violencia en el ámbito familiar o asimilado pero no de manera exclusiva, que afecta a las mujeres de manera desproporcionada, y en cuyo artículo 3.d) se refiere a la violencia contra la mujer por razones de género como toda violencia contra una mujer por el mero hecho de serlo o que afecte a estas de manera desproporcionada.

Además, indica la sentencia que la agravación de la pena por este motivo será de aplicación a todos aquellos supuestos en los que la descripción típica no haga referencia a factores de género, en virtud del principio de inherencia expresa o tácita (art. $67 \mathrm{CP}$ ). Por ello, cabe la aplicación de la circunstancia agravante genérica de discriminación por razones de género en los delitos contra la libertad sexual pues estos, ya desde la LO 3/1989 ${ }^{16}$, no son tipos género específicos en los que se

16 La Ley Orgánica 3/1989, de 21 de junio, de actualización del Código Penal modificó la rúbrica de los delitos contra la honestidad por la de delitos contra la libertad sexual y eliminó cualquier referencia al sujeto pasivo del delito, permitiendo la aplicación del tipo delictivo tanto en los supuestos en los que sujeto pasivo resultaba ser un hombre como si se trataba de una mujer. Desde ese momento, la valoración de las conductas en el Código Penal en relación con estos tipos delictivos cambia, de modo que "el enfoque de los delitos sexuales desde la perspectiva de la libertad presupone la superación de aquella adjudicación de roles y expectativas sociales diferenciados por razón del género. Si en la concepción anterior la limitación de la libertad de la mujer era el presupuesto de su honestidad y por ello lo que la hacía digna de protección, ahora se invierte el significado. Es la constricción de la libertad lo que colorea la ilicitud de la conducta” (Asúa Batarrita, 1998: 74). 
requiera que el sujeto pasivo sea una mujer y, además, "en la órbita de lo señalado por el Convenio de Estambul, la violencia sexual, especialmente en el ámbito de víctimas adultas, afecta desproporcionadamente a las mujeres" 17.

\subsubsection{El hombre como sujeto pasivo del delito}

La sentencia objeto del presente comentario no entra a valorar si en el sujeto pasivo debe concurrir el requisito de ser mujer, dado que los hechos probados se remiten al ámbito de las relaciones sexuales a cambio de precio en las que el sujeto activo es un hombre y el sujeto pasivo es una mujer. No obstante, este extremo sigue generando controversia en la doctrina y el Tribunal Supremo ha llegado a hacer alguna referencia en resoluciones precedentes.

No hago referencia en este caso a los supuestos en los que el hombre es sujeto pasivo del delito por el mero hecho de ser hombre (si ese supuesto existe $)^{18}$, sino a los posibles ataques que pueda sufrir un hombre cuando lleva a cabo un comportamiento no ajustado a los roles de género socialmente establecidos. Por ejemplo, un supuesto de la comisión de un delito de mobbing o acoso laboral que se basa de manera determinante en el hecho de que el sujeto pasivo, hombre, se acoge a los permisos legal y convencionalmente establecidos para poder hacerse cargo de un hijo sin que derive el cumplimiento de dichas obligaciones familiares a su cónyuge o pareja mujer.

En este sentido, algunos autores entienden que la presente circunstancia modificativa de la responsabilidad criminal "cubriría exclusivamente los casos de conductas machistas, esto es, las llevadas a cabo por varones frente a mujeres con la intención, consciente o subconsciente, de expresar su dominio y su trato hacia ellas como seres humanos inferiores" (Borja Jiménez, 2015: 122). Por el contrario, otros admiten su concurrencia a supuestos en los que el sujeto pasivo es hombre, pero lleva a cabo papeles ajenos al rol socioculturalmente establecidos. Por ejemplo, "si un hombre es bailarín de ballet, lo cual quizás choque para el autor

17 Epígrafe 1 del FJ tercero de la STS 444/2020, de 14 de septiembre.

18 Sí apunta en este sentido como motivo de aplicación de la circunstancia agravante de discriminación la Circular de la FGE núm. 7/2019, sobre pautas para interpretar los delitos de odio tipificados en el art. 510 CP. Esta, atendiendo a la neutralidad de los términos contenidos en los delitos por discriminación (también denominados delitos de odio), indica que "la vulnerabilidad del colectivo no es un elemento del tipo delictivo que requiera ser acreditado, sino que el legislador, haciendo ese juicio de valor previo, al incluirlo en el tipo penal, ha partido de esa vulnerabilidad intrínseca o situación de vulnerabilidad en el entorno social. Tampoco lo es el valor ético que pueda tener el sujeto pasivo. Así una agresión a una persona de ideología nazi, o la incitación al odio hacia tal colectivo, puede ser incluida en este tipo de delitos". No obstante, y aunque dicho extremo excede del presente estudio, no puedo mostrar mi conformidad con dicho posicionamiento. 
del delito con el tradicional rol patriarcal que le atribuye su género masculino, y ese autor (un hombre o una mujer) le mata por este motivo ('porque los hombres no bailan ballet'), se aplicará la agravante, con independencia del efecto intimidatorio que en un colectivo supuestamente caracterizado por un género pueda tener ese hecho" (Díaz López, 2016).

La Sentencia del Tribunal Supremo número 12/2020, de 23 de enero, viene a apuntar la posibilidad de aceptar que el sujeto pasivo sea un hombre, aunque lo hace de una manera poco concluyente. Así, en su fundamento jurídico segundo, indica que la agravante de discriminación por razones género "se establece en atención a la discriminación con que se trata a una persona por razón de su género, generalmente femenino, considerándola un ser inferior sometido al hombre por su propia naturaleza. El contenido negativo de esta actitud justifica la existencia de la agravante". Esto es, admite que generalmente el sujeto pasivo de estos delitos va a ser una mujer, pero no lo determina de manera excluyente.

Hay que tener en cuenta, en este sentido, que la motivación que la LO 1/2015 introduce en esta circunstancia modificativa de la responsabilidad criminal, como se ha indicado con anterioridad parte del Convenio de Estambul. En este, una vez definido el género en su artículo 3.c como "los papeles, comportamientos, actividades y atribuciones socialmente construidos que una sociedad concreta considera propios de mujeres o de hombres", en su artículo 3.d indica lo que se entiende por "violencia contra las mujeres por razones de género". Esta última descripción, por tanto, deja abierta la posibilidad de hablar de este tipo de violencia contra otros sujetos que no sean mujeres, por lo que al remitirse el legislador nacional a "razones de género" sin establecer ningún añadido respecto al sexo del sujeto pasivo, puede admitirse la comisión de un delito contra un hombre por este motivo en los términos descritos con anterioridad ${ }^{19}$.

\subsection{Elemento subjetivo}

Al margen de su fundamento y naturaleza, las circunstancias agravantes requieren, tal y como entienden tanto la doctrina como la jurisprudencia de manera pacífica, de la concurrencia de dos elementos, uno objetivo y otro subjetivo o intencional. De este modo, el primero se remite a toda suerte de datos, factores, caracterizaciones o acontecimientos referidos al objeto, es decir, de los que quedan fuera del ámbito del sujeto, al margen de la conciencia del sujeto y viene dada fuera de él, lo que no quiere decir, por tanto, que sea impersonal, mientras que el segundo supone la concurrencia de un conjunto de datos, situaciones o procesos

19 Para un mayor desarrollo de este extremo, Orejón Sánchez de las Heras (2019). 
referidos al sujeto; esto es, su modo de pensar, sus motivaciones y procesos de su psique que quedan al margen del objeto en sí.

En relación con el elemento subjetivo, todo incremento de la pena requiere, en virtud del principio de culpabilidad, que pueda ser reprochado a su autor, y para ello se exige que tuviera conocimiento de dicha ventaja o situación, es decir, "se requiere que el agente la haya buscado de propósito o que, al menos, se haya aprovechado intencionadamente, a sabiendas, de ella" (González Cussac, 1987: 509).

En cuanto a la circunstancia genérica de discriminación, el elemento subjetivo consiste en dos requisitos, por un lado "que el móvil del autor del delito debe ser alguna de las concretas circunstancias que expresamente se determinan" (motivos racistas, antisemitas o discriminación por razón de ideología, religión o creencias de la víctima, etnia, raza, nación, sexo, edad, orientación o identidad sexual o de género, razones de género, de aporofobia o de exclusión social, enfermedad o discapacidad) y, por otro lado, "perteneciendo la motivación delincuente a la esfera de su identidad, deberá acreditarse esta, a través de su conducta o manifestación externa, a la que no le serán ajenas los antecedentes de hecho, los coetáneos y los posteriores" (Ganzenmüller Roig, Escudero Moratalla y Frigola Vallina, 2000: 232).

Además, el Tribunal Supremo ha indicado de forma expresa que el motivo discriminatorio por el que se ha llevado a cabo el hecho típico debe ser determinante, y no simplemente concurrente. Así, ha llegado a referir que hay que atender al "elemento subjetivo atinente al ánimo o móvil especifico de actuar precisamente por alguna de las motivaciones a las que el precepto hace referencia, excluyendo, por consiguiente, aquellos supuestos en los que estas circunstancias carezcan del suficiente relieve o, incluso, no tengan ninguno. Resulta, por ello, innecesario señalar que no todo delito en el que la víctima sea una persona caracterizada por pertenecer a otra raza, etnia o nación o participar de otra ideología o religión o condición sexual, haya de ser aplicada la agravante. Se trata de una circunstancia que se fundamenta en la mayor culpabilidad del autor por la mayor reprochabilidad del móvil que impulsa a cometer el delito, siendo por ello requisito que aquella motivación sea la determinante para cometer el delito" 20 .

En concreto, y en relación con la agravante genérica de discriminación por razones de género, Borja Jiménez entiende que habría que identificar estos dos componentes, esto es, el objetivo relativo a la existencia real de la característica identitaria del sujeto pasivo, y otro referente al elemento subjetivo presente en el autor, es decir, el ánimo discriminatorio (Borja Jiménez, 2015: 120). En cualquier caso,

20 STS núm. 314/2015, de 4 de mayo. 
sería necesaria la concurrencia de ambos componentes para apreciar la agravante de discriminación por razones de género. De este modo la circunstancia modificativa exige acreditar "la presencia de una intención, actitud o situación de dominación del hombre sobre la mujer" (Marín de Espinosa, 2018: 18).

En este sentido, la Sentencia del Tribunal Supremo número 420/2018, de 25 de septiembre, hace referencia a que no toda agresión contra una mujer puede ser objeto de la circunstancia agravante de discriminación por razones de género, sino únicamente en aquellos supuestos en los que se acredita que la acción típica se ha llevado a cabo con "la intención de dominación del hombre sobre la mujer". Tanto es así que en esta resolución se remite a la Sentencia número 1177/2009, de 24 de noviembre que, en relación con un tipo género específico, refiere que no tienen cabida en el precepto los casos en los que "la acción agresiva no tiene connotaciones con la subcultura machista, es decir, cuando la conducta del varón no es expresión de una voluntad de sojuzgar a la pareja o de establecer o mantener una situación de dominación sobre la mujer colocando a ésta en un rol de inferioridad y subordinación en la relación con grave quebranto de su derecho a la igualdad, a la libertad y al respeto debido como ser humano en sus relaciones sentimentales".

Además, nuestros tribunales vienen a determinar que "los elementos fácticos de los que se desprenda la concurrencia de esas circunstancias que permiten la aplicación de la agravación, deben aparecer nítidamente en los hechos probados y, para ello, han de estar debidamente acreditados por prueba válida, suficiente y racional y expresamente valorada en la sentencia" 21 .

No obstante, el propio Tribunal Supremo ha ido flexibilizando este requisito en sus posteriores sentencias en relación con el delito cometido contra la mujer que tiene o había tenido una relación sentimental con el sujeto activo. Así, en la Sentencia número 99/2019, de 26 de febrero, haciendo una equiparación con los tipos penales introducidos mediante la LMPIVG y su legitimación por el Tribunal Constitucional, entre otras, en su Sentencia número 59/2008, de 14 de mayo, indica que, en ese concreto ámbito relacional, "bastará para estimarse aplicable la agravante genérica que el hecho probado de cuenta de la relación típica prevista en los tipos penales antes citados de tal suerte que el delito se entienda como

21 AP València, Sección Primera, núm. 369/2019, de 26 de julio. Esta misma sentencia indica expresamente en el supuesto enjuiciado y como justificación para no aplicar la agravante genérica de discriminación por razones de género que la conducta del sujeto activo hombre sobre el sujeto pasivo mujer, entre quienes había una relación conyugal pasada, "no es expresión de una voluntad de sojuzgar a la pareja o de establecer o mantener una situación de dominación sobre la mujer colocando a ésta en un rol de inferioridad y subordinación en la relación, su ánimo como hemos subrayado es la de matarla, sin plantearse ninguna otra cuestión". 
manifestación objetiva de la discriminación característica de la misma. $\mathrm{Y}$, en lo subjetivo, bastará la de tal relación unida a la de cometer el delito de que se consciencia voluntad trate diversos de aquéllos".

Así, parecía, no obstante, y en los supuestos en los que el sujeto activo y el sujeto pasivo no estaban unidos o no habían estado unidos por una relación conyugal o análoga a esta, que debía acreditarse de manera fehaciente el componente intencional consistente en el actuar del sujeto activo con una manifiesta voluntad de subyugar a la mujer por el mero hecho de serlo.

La sentencia objeto del presente comentario se separa de dicho posicionamiento e indica expresamente que "no requiere la agravante de un elemento subjetivo específico entendido como ánimo dirigido a subordinar, humillar o dominar a la mujer, (así lo hemos dicho en la STS 99/2019) pero sí que objetivamente, prescindiendo de las razones específicas del autor, los hechos sean expresión de ese desigual reparto de papeles al que es consustancial la superioridad del varón que adquiere así efecto motivador. Todo ello determinado a partir de las particulares circunstancias que rodean los hechos y del contexto relacional de agresor y víctima, no limitado al ámbito conyugal o de pareja, desde luego no lo impone el precepto (artículo $22.4 \mathrm{CP}$ ), sino a todos aquellos en los que se conciten hombres y mujeres, y sean susceptibles de reproducir desiguales esquemas de relación que están socialmente asentados. Por ello bastará para estimarse aplicable la agravante genérica que el hecho probado dé cuenta de tales elementos que aumentan el injusto, porque colocan a la mujer víctima en un papel de subordinación que perpetúa patrones de discriminación históricos y socialmente asentados; y en lo subjetivo, que al autor haya asumido consciente y voluntariamente ese comportamiento que añade el plus de gravedad".

Así, y respecto al elemento subjetivo, no va a ser necesario, según el posicionamiento del Tribunal Supremo, un concreto y específico ánimo machista en el sujeto activo tendente a obtener la subordinación de la mujer por el hombre, sino únicamente que aquel, mediante su actuación, lo que haga sea perpetuar esa situación de subordiscriminación socialmente concurrente. De este modo, el elemento subjetivo, y que guarda relación directa con el principio de culpabilidad, se difumina mediante la aceptación de una actuación del sujeto activo bajo el conocimiento de la situación de discriminación socialmente existente, con independencia de su expresa y concreta voluntad.

\section{Consideraciones finales}

El legislador ha optado por regular los delitos de violencia sobre la mujer mediante dos sistemas o modos diferenciados. De un lado ha creado tipos género específicos que guardan relación con la violencia 
de género entendida en los términos establecidos en el artículo 1 de la LO 1/2004, de Medidas de protección integral contra la violencia de género, esto es, aquella que "como manifestación de la discriminación, la situación de desigualdad y las relaciones de poder de los hombres sobre las mujeres, se ejerce sobre éstas por parte de quienes sean o hayan sido sus cónyuges o de quienes estén o hayan estado ligados a ellas por relaciones similares de afectividad, aun sin convivencia”. De otro lado, ha regulado la violencia por razones de género tal y como viene establecida en el Convenio de Estambul, esto es, ampliando su margen de actuación a todos los actos de violencia basados en los papeles, comportamientos, actividades y atribuciones socialmente construidos que una sociedad concreta considera propios de mujeres o de hombres, sin que entre los sujetos intervinientes tenga que existir una determinada relación de afectividad presente o pasada y que pueden suponer violencia física, sexual, psicológica o económica.

En este último supuesto, esto es, la violencia por razones de género, el Código penal contempla, por una parte, una circunstancia agravante genérica de discriminación por razones de género reconocida en su artículo $22.4^{\mathrm{a}} \mathrm{y}$, por otra, tipos específicos que sancionan determinadas conductas basadas en la discriminación por ese motivo ${ }^{22}$. Modelo político criminal mixto que no resulta ajeno a la tradición legislativa en nuestro ordenamiento jurídico penal.

No obstante, al reconocer como circunstancia modificativa de la responsabilidad criminal la discriminación por razones de género, no se ha creado una agravante genérica de nueva redacción como una más de entre las previstas legalmente, como se ha planteado en diversas ocasiones en sede parlamentaria, sino que ha introducido las razones de género como una de las motivaciones expresamente contempladas en la circunstancia cuarta del artículo 22 del Código penal. Ello supone que cualquier interpretación que se haga debe tener en cuenta la interpretación que tanto la doctrina como la jurisprudencia han desarrollado en relación con esta circunstancia desde su introducción en nuestro ordenamiento jurídico mediante LO 4/1995, por la que "lo que no iba a ser sino una ampliación del ámbito de prohibición del genocidio, claramente circunscrito por tanto a conductas de simpatía ideológica filo-nazi, acaba incluyendo también un delito de provocación a la discriminación y una agravante genérica para los delitos contra las personas y el patrimonio por motivos racistas o antisemitas, étnicos y nacionales, pero también, por razones puramente ideológicas, religiosas o de creencias" (Landa, 2004: 63).

22 Arts. 510.1 , 510.2, 511, 512 y 607 bis, todos ellos del Código penal, a los que hay que añadir los artículos 170.1 y $174 \mathrm{CP}$, que no reconocen expresamente las razones de género, pero disponen de una cláusula numerus apertus como motivación de la acción del sujeto activo. 
Queda pendiente aún por determinar si, como algunos autores postulan, y entiendo que se ajusta a una interpretación literal del precepto, así como al fundamento de la agravante, cabe entender que la circunstancia es aplicable a supuestos en los que el sujeto pasivo sea varón. Ello siempre que el motivo de la acción delictiva sea que el mismo no se ajusta, desde la perspectiva del sujeto activo, a los roles socialmente establecidos a hombres y mujeres (por ejemplo, un delito de mobbing o acoso laboral que se basa de manera exclusiva en el hecho de que el sujeto pasivo, hombre, se acoge a los permisos legal y convencionalmente establecidos para poder hacerse cargo de un hijo). A esto parece apuntar la Sentencia del Tribunal Supremo número 12/2020, de 23 de enero, cuando en su fundamento jurídico segundo indica que la agravante de discriminación por razones género se establece en atención a la discriminación con que se trata a una persona por razón de su género, general -pero no exclusivamente- femenino.

La sentencia objeto del presente estudio entiende que no cabe acreditar "un elemento subjetivo específico entendido como ánimo dirigido a subordinar, humillar o dominar a la mujer", sino que basta con que objetivamente "los hechos sean expresión de ese desigual reparto de papeles al que es consustancial la superioridad del varón que adquiere así efecto motivador". Esta conclusión viene a establecer una interpretación sobre la discriminación por razones de género diferente a lo que se ha venido exigiendo en el supuesto de que la motivación discriminatoria del sujeto activo sea otra de las expresamente reconocidas, como el racismo y la homofobia, bifobia o transfobia. Así, el Tribunal Supremo ha llegado a determinar en otros supuestos que la circunstancia agravante de discriminación "toma como fundamento para afirmar la necesaria concurrencia del específico móvil discriminatorio en la conducta de los acusados" ${ }^{23}$, de modo que es necesario acreditar ese elemento subjetivo específico en cada caso.

No es admisible esta excepcionalidad en uno de los motivos objeto de discriminación, debiendo exigirse la necesaria acreditación del elemento subjetivo y que, al tratarse del móvil del mismo y encontrarse este en la psique del sujeto activo, corresponde extraerlo de prueba indiciaria. Prueba que no resulta de imposible práctica pues basta comprobar los hechos declarados probados en la sentencia objeto de estudio para acreditar la concurrencia del elemento subjetivo específico en expresiones como "el procesado se negó a abonar cualquier importe, golpeándole fuertemente en el rostro al tiempo que le decía ¿te enteras ya cómo va esto?" y la existencia de "un clima de violencia y sometimiento".

${ }^{23}$ STS núm. 386/2020, de 9 de julio. 


\section{Bibliografía}

Asúa Batarrita, A. (1998). Las agresiones sexuales en el nuevo Código Penal: imágenes culturales y discurso jurídico. En AA.VV., Análisis del código penal desde la perspectiva de género (pp. 47-101). Vitoria: Emakunde-Instituto Vasco de la Mujer.

Boix Reig, J. (2003). La protección penal de las libertades. Discurso de ingreso como Académico de número en la Real Academia Valenciana de Jurisprudencia y Legislación, València, 9 de enero de 2003.

BoRJA JiménEZ, E. (2015). La circunstancia agravante de discriminación del art. 22.4․ En J. L. González Cussac (dir.). Comentarios a la reforma del Código Penal de 2015 (pp. 119-123). València: Tirant lo Blanch.

De Lucas Martín, F. J. (2020). Decir no. El imperativo de la desobediencia. València: Tirant lo Blanch.

DÍAz LÓPEZ, J.A. (2015). La reforma de la agravante genérica de discriminación. Trabajo presentando en la conferencia efectuada en la Real Academia de Jurisprudencia y Legislación de Madrid, 22 de junio de 2015.

DíAz López, J. A. (2016). Una agravante por motivos discriminatorios referidos al género de la víctima. Revista Internacional Derecho Penal Contemporáneo, 54.

Gallego Sánchez, G. (2015). El Convenio de Estambul. Su incidencia en el sistema español de lucha frente a la violencia contra la mujer. Revista de Jurisprudencia, 2.

Ganzenmüller Roig, C., Escudero Moratalla, J. F. y Frigola Vallina, J. (2000). Eximentes, atenuantes y agravantes en el Código penal de 1995. Personas criminalmente responsables. Barcelona: Bosch.

GonzÁlez Cussac, J. L. (1987). Teoría general de las circunstancias modificativas de la responsabilidad criminal (Tesis doctoral). Universitat de València, Facultad de Derecho, València.

LANDA GoRISTIZA, J. M. (2004). Racismo, xenofobia y Estado democrático. Eguzkilore: Cuaderno del Instituto Vasco de Criminología, 18 (pp. 5972).

Laurenzo Copello, P. (2015). ¿Hacen falta figuras género específicas para proteger mejor a las mujeres? Estudios Penales y Criminológicos, 35 (pp. 783-830).

Lloria García, P. (2020). Algunas reflexiones sobre la perspectiva de género y el poder de castigar del Estado. Estudios Penales y Criminológicos, 40 (pp. 309-357).

Lloria GARCIA, P. (2019). La regulación penal en materia de violencia familiar y de género tras la reforma de 2015. Especial referencia al ámbito tecnológico. Revista General de Derecho Penal, 31. 
Marín de Espinosa CeBallos, E. B. (2018). La agravante genérica de discriminación por razones de género (art. 22.4 CP). Revista Electrónica de Ciencia Penal y Criminología, 20-27.

OREJón SÁNCHEz de las HeRAs, N. (2019). Discriminación por razones de género: el concepto 'género' en el ordenamiento jurídico penal español. IgualdadES, 1 (pp. 159-183).

Rueda MARtín, M. á Á. (2019). Cometer un delito por discriminación referente al sexo de la víctima y/o por razones de género como circunstancia agravante genérica. Revista Electrónica de Ciencia Penal y Criminología, 21-04.

VAleiJe Álvarez, I. (1999). La víctima en los delitos contra la libertad sexual. Estudios penales y criminológicos, 22 (pp. 309-354).

\section{Jurisprudencia}

STS núm. 1145/2006, de 23 de noviembre.

STC núm. 59/2008, de 14 de mayo.

STS núm. 1177/2009, de 24 de noviembre.

STS núm. 314/2015, de 4 de mayo.

STS núm. 79/2016, de 10 de febrero.

STS núm. 420/2018, de 25 de septiembre.

STS núm. 565/2018, de 19 de noviembre.

STS núm. 584/2018, de 23 de noviembre.

STS núm. 99/2019, de 26 de febrero.

STS núm. 12/2020, de 23 de enero.

STS núm. 386/2020, de 9 de julio.

STS núm. 444/2020, de 14 de septiembre.

Stc. AP València, Sección Primera, núm. 369/2019, de 26 de julio. 